\title{
Space weather impact on the equatorial and low latitude F-region ionosphere over India
}

\author{
R. S. Dabas ${ }^{1}$, R. M. Das ${ }^{1}$, V. K. Vohra ${ }^{1}$, and C. V. Devasia ${ }^{2}$ \\ ${ }^{1}$ Radio and Atmospheric Sciences Division, National Physical Laboratory, New Delhi-110012, India \\ ${ }^{2}$ Space Physics Laboratory, Vikram Sarabhai Space Center, Trivandrum - 695 022, India
}

Received: 25 January 2005 - Revised: 7 October 2005 - Accepted: 28 November 2005 - Published: 7 March 2006

\begin{abstract}
For a detailed study of the space weather impact on the equatorial and low latitude F-region, the ionospheric response features are analysed during the periods of three recent and most severe magnetic storm events of the present solar cycle which occurred in October and November 2003, and November 2004. The F-layer base height $\left(h^{\prime} \mathrm{F}\right)$, peak height $(h m \mathrm{~F} 2)$ and critical frequency $(f o \mathrm{~F} 2)$ data, from Trivandrum, an equatorial station and Delhi, a low latitude location, are examined during the three magnetic storm periods. The results of the analysis clearly shows that the height of the Fregion (both $h^{\prime} \mathrm{F}$ and $h m \mathrm{~F} 2$ ), at the equator and low latitude, simultaneously increases by 200 to $300 \mathrm{~km}$, in association with maximum negative excursion of $D_{s t}$ values around the midnight hours with a large depletion of ionization over the equator, which is followed by an ionization enhancement at low latitude during the recovery phase of the storm. At Delhi, fast variations up to $200 \mathrm{~m} / \mathrm{s}$ are also observed in the F-layer vertical upward/downward velocity, calculated using Doppler shifts, associated with the maximum negative excursion of $D_{s t}$. This shows that during magnetic disturbances, the equatorial ionization anomaly (EIA) expands to a much wider latitude than the normal fountain driven by the E/F-layer dynamo electric fields. It is also observed that during the main phase of the storm, at low latitude there is generally an enhancement of F-region ionization with an increase in $h^{\prime} \mathrm{F} / h m \mathrm{~F} 2$ but in the equatorial region, the ionization collapses with a decrease in $h^{\prime} \mathrm{F} / h m \mathrm{~F} 2$, especially after sunset hours. In addition, at the equator the normal pre-sunset hours' enhancement in $h^{\prime} \mathrm{F}$ is considerably suppressed during storm periods. This might be due to changes in magnitude and direction of the zonal electric field affecting the upward $\boldsymbol{E} \times \boldsymbol{B}$ drift and hence the plasma distribution in the form of a decrease in electron density in the equatorial region and an increase in the low latitude region. In association with disturbance electric fields, the enhanced storm-induced
\end{abstract}

Correspondence to: R. S. Dabas

rajdabas@nplindia.ernet.in equatorward meridional winds in the thermosphere can also further amplify the F-layer height rise at low latitudes during the post-midnight hours, as observed in two of the storm periods.

Keywords. Ionosphere (Equatorial ionosphere; Ionosphere magnetosphere interactions;Ionospheric disturbances)

\section{Introduction}

The effect of space weather over the equatorial and low latitudinal ionosphere has great importance due to its unique features. A number of studies have been conducted on low latitudinal ionospheic responses during magnetic storm periods that have significantly advanced our knowledge on this subject (Kelley et al., 1979; Dabas and Jain, 1985; Abdu et al., 1990, 1995; Fejer, 1991; Lakshmi el al., 1997; de Medeiros et al., 1997; Sobral et al., 1997; Abdu, 1997; Sastri et al., 2000; Abdu, 2001; Sastri et al., 2002; Pincheira et al., 2002; Lobzin and Pavlov, 2002a, 2002b; Pavlov et al., 2004; Lynn et al., 2004 and Lima et al., 2004). Evidence has been provided by Fesen et al. (1989) for the effect of winds blowing across the magnetic equator transporting plasma along the nearly horizontal field lines. A recent study by Sobral et al. (2001) presented some cases of $f o \mathrm{~F} 2$ increases over low latitudes to be related to an enhanced plasma fountain. Burns et al. (1995) reported the occurrence of adiabatic heating at low latitudes as a result of downwelling from the storm-time changes in the global thermospheric circulation. Abdu (1997 and 2001) presented comprehensive reviews; one on the major phenomena of the equatorial ionosphere-thermosphere system under disturbed conditions and the second on outstanding problems in the equatorial ionosphere-thermosphere electrodynamics relevant to spread-F. It was reported that during disturbed conditions, modifications to the Equatorial Ionisation Anomaly (EIA), Equatorial Spread-F (ESF) 
Table 1. Summary of the magnetic storms.

\begin{tabular}{lllcccc}
\hline Starting Date & $\begin{array}{l}\text { Type of } \\
\text { Mag. storm }\end{array}$ & Start Time (LT) & $\begin{array}{l}K_{p} \text {-Index } \\
\text { maximum }\end{array}$ & $\begin{array}{l}D_{s t} \text { max. } \\
\text { negative excursion (-nT) }\end{array}$ & Ending Date & $\begin{array}{l}\text { End Time } \\
(\mathrm{LT})\end{array}$ \\
\hline 29 Oct. 2003 & SC & $11: 43$ & 90 & -308 & 30 Oct. 2003 & $22: 00$ \\
30 Oct. 2003 & SC & $22: 00$ & 90 & -347 & 1 Nov. 2003 & $04: 00$ \\
20 Nov. 2003 & SC & $13: 33$ & $9-$ & -429 & 21 Nov. 2003 & $22: 00$ \\
7 Nov. 2004 & SC & $11: 00$ & $9-$ & -383 & 9 Nov. 2004 & $07: 00$ \\
9 Nov. 2004 & SC & $07: 00$ & $9-$ & -296 & 14 Nov. 2004 & $03: 00$ \\
\hline
\end{tabular}

and Equatorial Electrojet (EEJ) are produced by disturbance electric fields resulting from prompt equatorward penetration of magnetospheric/high latitude electric fields, by a disturbance dynamo which is driven by enhanced global thermospheric circulation resulting from energy input at high latitude, and by disturbance winds (zonal and meridional) modifying the equatorial thermospheric dynamics. Pincheira et al. (2002) studied the ionospheric and thermospheric responses to magnetic storm disturbances over the South American sector using $f_{o} \mathrm{~F} 2, h m \mathrm{~F} 2$ and the neutral winds extracted from measured $h m \mathrm{~F} 2$, using the Interhemispheric Plasma (FLIP) model. It is reported that EIA can undergo enhancement due to the magnetospheric disturbance electric fields which penetrate to low latitudes during the growth phase of a storm/sub-storm, whereas EIA inhibition occurs more often under a disturbance dynamo (DD) electric field. The relative roles of different mechanisms responsible for the suppression of the equatorial anomaly were studied numerically by Pavlov et al. (2004). A detailed statistical study of the negative storm-time disturbances based on ionosondes data was carried out by Lobzin and Pavlov (2002a, 2002b). Also, season-dependent meridional/transequatorial winds can significantly alter the EIA response to disturbance electric fields. Lima et al. (2004) studied the response of the equatorial and low latitude ionosphere during a storm in April 2002 and the observed F-region parameters when compared with the TIMEGCM model show reasonable agreement during magnetic disturbances. Lynn et al. (2004), using a combination of TOPEX/Poseidon TEC and ionosonde observations, studied the cases of storms showing a strong depression in daytime $f_{o} \mathrm{~F} 2$ values at low latitudes which are caused by the suppression in the equatorial ionization anomaly. Some studies on the ionospheric response to magnetic storms have been conducted over India using ionosonde data. The response of the equatorial and low latitude F-region to the great magnetic storm of 13 March 1989 was studied by Lakshmi et. al. (1991), who used ionosonde data available for various equatorial and low latitudinal stations in India. The studies by Kotadia and Ramanathan (1962) and Kotadia (1962) presented cases of negative ionospheric responses over the entire latitude range around the geomagnetic equator. Sastri et al. (2002) studied the response of the equatorial ionosphere in the Indian midnight sector to the severe magnetic storm of 15 July 2000 and reported a remarkably large downward movement of the F-region simultaneously at locations throughout the equatorial region, due to a short-lived westward electric field disturbance.

The purpose of this paper is to examine the behaviour of the ionosphere over the Indian equatorial and low latitude regions during the three most severe storms which occurred on 29 October 2003, 20 November 2003 and 7 November 2004. For this purpose ionospheric F2 layer parameters, foF $2, h^{\prime} \mathrm{F}$ and $h m \mathrm{~F} 2$, obtained from two stations, namely Delhi $(28.3 \mathrm{~N}, 77.1 \mathrm{E}$, dip $42.4 \mathrm{~N})$ and Trivandrum $(8.2 \mathrm{~N}$, $76.9 \mathrm{E}$, dip $0.6 \mathrm{~N}$ ), are analysed in this paper for the three magnetic storms of 29 October, 20 November 2003, and the most recent one on 7 November 2004. The above storms are rated as the most severe storms of the current solar cycle number 23 .

\section{Data and analysis}

The data used for the present study are hourly values of the ionospheric parameters obtained from the digital ionosondes operateing in New Delhi (a low latitude location north of EIA crest) and Trivandrum (an equatorial station), respectively, during the specific time period of the three magnetic storms. Both digital ionosondes are fully computer-controlled systems, and they operate in the vertical incidence mode and provide information on various ionospheric parameters, such as $f o \mathrm{~F} 2, h^{\prime} \mathrm{F}, h m \mathrm{~F} 2$, foEs, etc. Although both ionosondes have computerized scaling capability, all data were scaled manually. The $h m \mathrm{~F} 2$ values are obtained using the simplified formulation given by Dudeney (1983). It is to be pointed out here that the value of $h m \mathrm{~F} 2$ is a function of $\mathrm{M}(3000) \mathrm{F} 2$ and foE. During nighttime, when foE measurements are not available, the magnitude of $h m \mathrm{~F} 2$ so obtained is slightly overestimated. Therefore, nighttime $h m \mathrm{~F} 2$ values used in the present study are slightly-overestimated. To study the impact of the magnetic storm on the equatorial and low latitudinal ionosphere, during the three storms of October and November 2003 and the most recent one in November 2004, the F-region parameters, $f_{o} \mathrm{~F} 2, h^{\prime} \mathrm{F}$ and $h m \mathrm{~F} 2$, over Trivandrum and Delhi, are analysed in relation to quiet-day values of these parameters closest to the respective storm times. Table 2 gives the list of study days including a reference quiet day for each of the three storms, along with the daily solar 
Table 2. The list of study days, including reference quiet day, for each of the three storms, along with the daily solar activity index, F10.7, and magnetic activity index, $\Sigma K_{p}$, and the range of $K_{p}$ index for the reference quiet days. Limits of changes in the $K_{p}$ index for quiet days is marked.

\begin{tabular}{llllll}
\hline STORM-1 & \multicolumn{3}{l}{ STORM-2 } & \multicolumn{3}{l}{ STORM-3 } \\
\hline Date & F10.7 & Date & F10.7 & Date & F10.7 \\
\hline $10 / 27 / 2003^{*}$ & 257 & $11 / 28 / 2003 * *$ & 144 & $11 / 5 / 2004^{* * *}$ & 141 \\
$10 / 28 / 03$ & 274 & $11 / 19 / 03$ & 155 & $11 / 06 / 04$ & 129 \\
$10 / 29 / 03$ & 279 & $11 / 20 / 03$ & 175 & $11 / 07 / 04$ & 130 \\
$10 / 30 / 03$ & 271 & $11 / 21 / 03$ & 177 & $11 / 08 / 04$ & 124 \\
$10 / 31 / 03$ & 249 & $11 / 22 / 03$ & 176 & $11 / 09 / 04$ & 127 \\
$11 / 01 / 03$ & 210 & $11 / 23 / 03$ & 178 & $11 / 10 / 04$ & 105 \\
& & & & $11 / 11 / 04$ & 95 \\
\hline
\end{tabular}

* varies from 1 to $3, * *$ varies from 0 to 2 , *** varies from 0 to $3-$

activity index F10.7 and magnetic activity index $\Sigma K_{p}$ and the range of $K_{p}$ index for the reference quiet days. $D_{s t}$ and $K_{p}$-index values during the specific storm periods are obtained from the World Data Center.

\section{Results}

The general interval of October-November 2003 and November 2004 are important for the study of the ionosphere due to the three most severe magnetic storms (details of which are given in Table 1) of the current solar cycle number 23 which occurred during these periods. The storm intensity in all three events was so high that the $K_{p}$ value reached $9_{-}$to $9_{0}$ during these storms. As seen from Table 1 all three magnetic storms were reported as the sudden commencement (SC) type and the maximum negative excursion of $D_{s t}$ for the three storms generally varied between $-325 \mathrm{nT}$ and $-450 \mathrm{nT}$. In this paper we present and discuss the disturbance variations of the parameters $f o \mathrm{~F} 2, h^{\prime} \mathrm{F}$ and $h m \mathrm{~F} 2$ during each magnetic storm.

\subsection{Magnetic storm of 29 October 2003}

The storm of 29 October 2003 started with an SC at 06:13 UT (11:43 LT) and the maximum negative excursion in $D_{s t}$ of $-308 \mathrm{nT}$ was reached in the local early morning hours, at 05:00 LT, on 30 October, which was followed by a recovery phase that lasted until the late evening of 30 October. Subsequently, a more intense storm set in with the $D_{s t}$ value reaching a maximum excursion of $-347 \mathrm{nT}$ at $03: 30 \mathrm{LT}$ on 31 October 2003. The $K_{p}$ value during this period reached $9_{0}$ . Figure 1 shows, during the interval October 28 to November 1 , the $f o \mathrm{~F} 2, h^{\prime} \mathrm{F}$ and $h m \mathrm{~F} 2$ deviations from their nearest quiet-day value for Delhi and Trivandrum. From the figure it is clearly observed that, at Delhi, during the daytime of 29 October, $f o \mathrm{~F} 2$ raises by more than $4 \mathrm{MHz}$ from its quiet-day values with corresponding increases in $h^{\prime} \mathrm{F}$ and
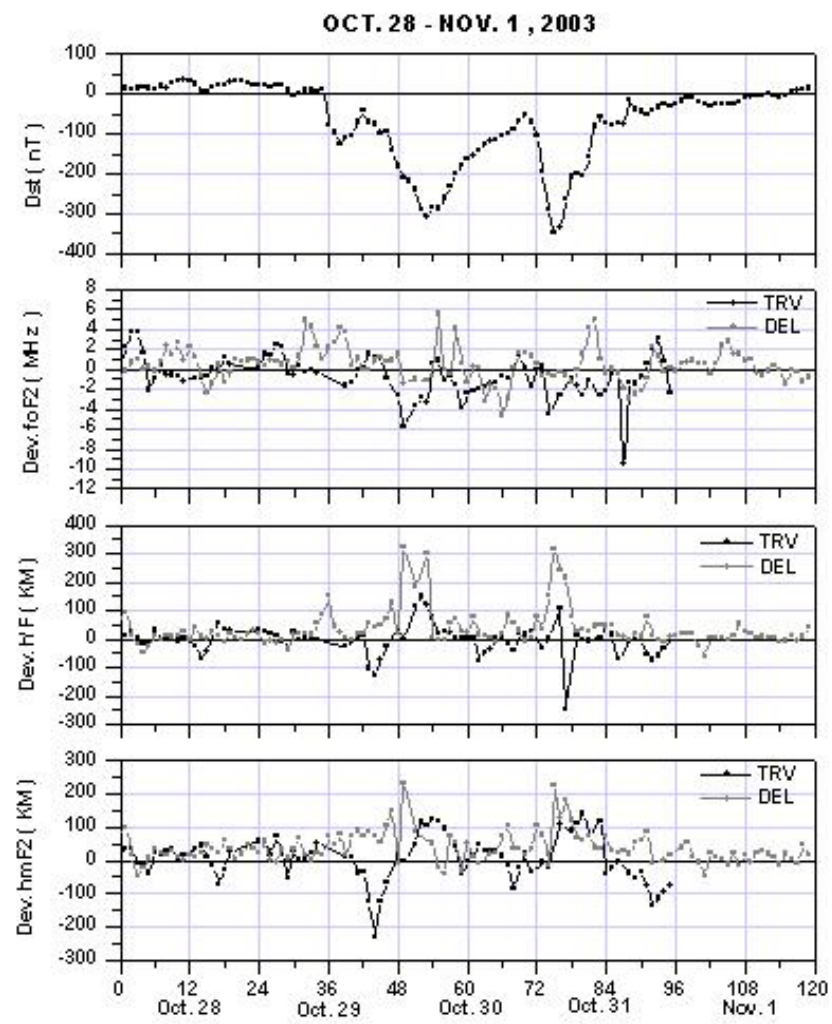

LT

Fig. 1. Shows the deviation in $f o \mathrm{~F} 2, h^{\prime} \mathrm{F}$ and $h m \mathrm{~F} 2$ from the quiet day values at low latitudinal station Delhi in dark line and equatorial station Thumba (Trivendrum) in shaded line with $D_{s t}$ during the severe magnetic storm of 30 October 2003.

$h m \mathrm{~F} 2$ by more that $100 \mathrm{~km}$ and $75 \mathrm{~km}$, respectively; $f o \mathrm{~F} 2$, $h m \mathrm{~F} 2$ and $h^{\prime} \mathrm{F}$ remain higher than the quiet day values until midnight but then there is sudden and drastic increases in $h^{\prime} \mathrm{F}$ and $h m \mathrm{~F} 2$, with a deviation reaching up to a maximum of $300 \mathrm{~km}$ and $200 \mathrm{~km}$, respectively, above their quiet-day values, until about sunrise time (30 October). During this height increase the $f o \mathrm{~F} 2$ values showed a sudden decrease, which is contrary to a daytime behaviour where $f o \mathrm{~F} 2$ is expected to increase with the increases in $h^{\prime} \mathrm{F}$ and $h m \mathrm{~F} 2$. On 30 October, for which the recovery phase of the storm was in progress, daytime $f o \mathrm{~F} 2$ values show a sinusoidal variation similar to that of travelling ionospheric disturbances (TIDs) with a similar $h^{\prime} \mathrm{F}$ variation. On the following night (i.e. on the night of 30-31 October) another severe magnetic storm sets in at 22:00 LT when the $D_{s t}$ value reached $-347 \mathrm{nT}$ during the post midnight hours (at 03:00 LT) over the observing site. Corresponding to this $D_{s t}$ variation there is again a sudden and dramatic increase in both $h^{\prime} \mathrm{F}$ and $h m \mathrm{~F} 2$, with a deviation reaching more than $300 \mathrm{~km}$ and $200 \mathrm{~km}$, respectively, above their quiet-day values, without much change in the $f o \mathrm{~F} 2$ values. During the recovery phase of this second storm, there was again as increase up to $5 \mathrm{MHz}$ in the daytime $f o \mathrm{~F} 2$ values but without any change in the corresponding $h^{\prime} \mathrm{F}$ values, whereas $h m \mathrm{~F} 2$ values remain higher 

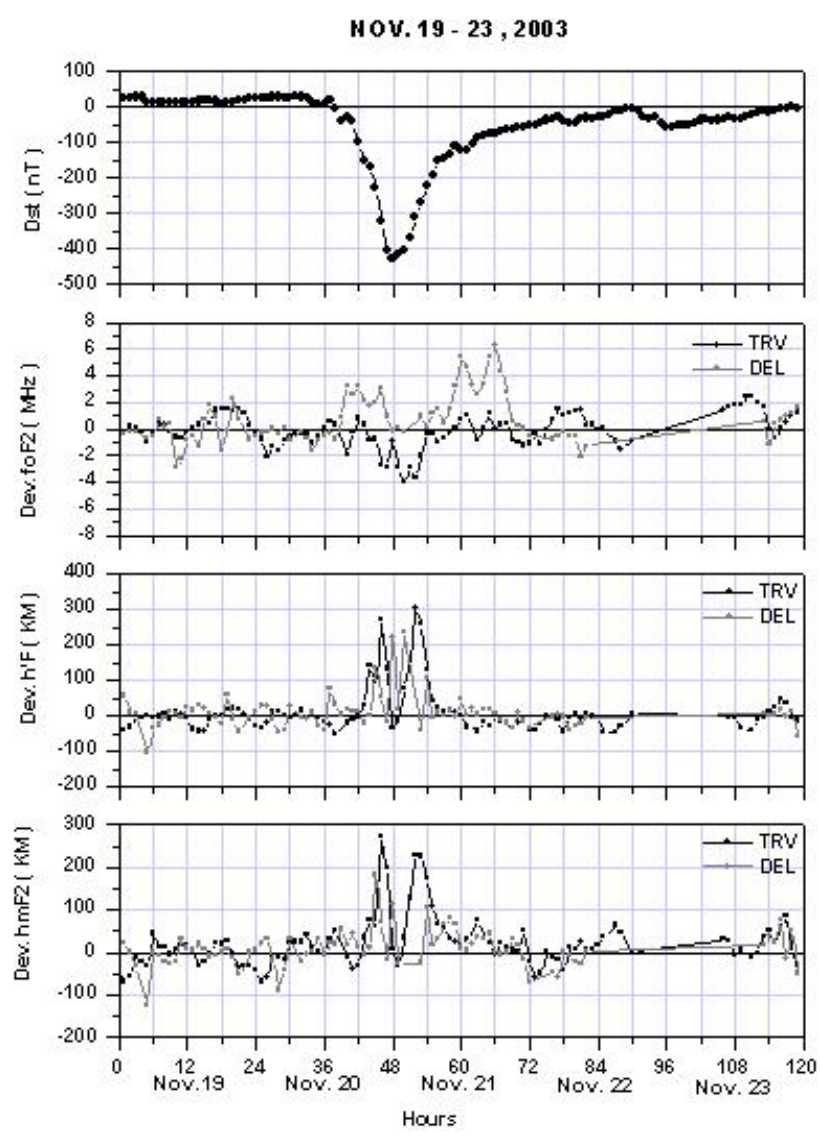

Fig. 2. Shows the deviation in $f o \mathrm{~F} 2, h^{\prime} \mathrm{F}$ and $h m \mathrm{~F} 2$ from the quiet-day values at the low latitudinal station Delhi in a dark line and the equatorial station Thumba (Trivendrum) in a shaded line, with $D_{s t}$ during the severe magnetic storm of 20 November 2003.

than the quiet-day values. On the following day (1 November 2003) $f o \mathrm{~F} 2, h m \mathrm{~F} 2$ and $h^{\prime} \mathrm{F}$ return to their normal quietday variations. The above results from Delhi give clear evidence of a daytime enhancement and night-time decrease in F-region ionization during the magnetic storm periods, with both $h^{\prime} \mathrm{F}$ and $h m \mathrm{~F} 2$ showing sudden increases up to $250 \mathrm{~km}$ and $350 \mathrm{~km}$, respectively, from their quiet day values during post-midnight hours in both storm cases. The sharp rise in the $h^{\prime} \mathrm{F}$ and $h m \mathrm{~F} 2$ values seems to occur during the main phase of the storm, marked by a sharp fall in the $D_{s t}$ values.

Regarding the $f o \mathrm{~F} 2, h m \mathrm{~F} 2$ and $h^{\prime} \mathrm{F}$ variations at the equatorial location it is observed (in Fig. 1) that the F-region ionization becomes drastically depleted during the period of the main phase of the storm, i.e. on the night of 29-30 October 2003 , as can be noted in the drastic decrease in $f o \mathrm{~F} 2$ by about $5 \mathrm{MHz}$ with respect to its quiet-day values. The fall in ionization at Trivandrum continued up to the pre-dawn hours and rapidly start to recover with the onset of local sunrise. An interesting feature noted in $h^{\prime} \mathrm{F}$ and $h m \mathrm{~F} 2$ variations during the storm main phase is the large decrease up to $125 \mathrm{~km}$ and $230 \mathrm{~km}$, respectively, in the $h^{\prime} \mathrm{F}$ and $h m \mathrm{~F} 2$ values from the quiet-day values during pre-sunset hours which indicates the suppression of the usual sunset enhancement in $h^{\prime} \mathrm{F}$ during magnetic disturbances (Rishbeth, 1971; Dabas et al., 1989). During the post-midnight hours, corresponding to the $D_{s t}$ maximum negative excursion, there is a sudden increase in both $h m \mathrm{~F} 2$ and $h^{\prime} \mathrm{F}$ values by more than $200 \mathrm{~km}$ and $100 \mathrm{~km}$, respectively, from their nearest quiet day values on the night of 29-30 October 2003, which is coincident with the sudden fall in $f o \mathrm{~F} 2$ values by $6 \mathrm{MHz}$ from the quiet-day values. It may be noted further that the above variations occur prior to the start of the recovery phase. From the above results of the $f o \mathrm{~F} 2, h m \mathrm{~F} 2$ and $h^{\prime} \mathrm{F}$ variations at the equatorial station Trivandrum and low latitude station Delhi, it is noted that during the daytime, the value of $f o \mathrm{~F} 2$ generally increases at low latitude and decreases at the equatorial location, and the corresponding $h m \mathrm{~F} 2$ and $h^{\prime} \mathrm{F}$ values also show similar variations, during magnetic storms. During post-midnight hours, under the $D_{s t}$ maximum negative excursion phase, there is a sudden increase in both $h m \mathrm{~F} 2$ and $h^{\prime} \mathrm{F}$ values, at both locations, but the relative enhancement is more at the low latitude station as compared to the equatorial station in the storm cases (see Fig. 1), whereas a sudden collapse of $f o \mathrm{~F} 2$ is observed only at the equatorial location.

\subsection{SC Magnetic Storm of 20 November 2003}

A second severe storm occurred at around 08:03 UT (13:33 LT) on 20 November 2003. The top panel of Fig. 2 shows the $D_{s t}$ variations for this storm and the bottom panels, respectively, give the corresponding deviations of $f o \mathrm{~F} 2$, $h^{\prime} \mathrm{F}$ and $h m \mathrm{~F} 2$ from their reference quiet-day values. As seen from Fig. 2, the maximum negative excursion of $D_{s t}$ reached $-429 \mathrm{nT}$ around local midnight on the night of 20 21 November, followed by the recovery phase. The reported maximum $K_{p}$ in this case was also $9_{-}$. As compared to the two successive storms of October 2003 this one is a clean storm. In this case an enhancement in $f o \mathrm{~F} 2$ is also observed at Delhi, starting from the afternoon hours until local midnight hours of 20 November, when the main phase of the storm is in progress without much change from midnight to around the sunrise period. But on 21 November 2003, starting from sunrise until the evening hours, and during the storm recovery phase, a large enhancement is observed in $f o \mathrm{~F} 2$ values up to $6 \mathrm{MHz}$ over Delhi which returned to normal values after the sunset hours. In contrast to the Delhi $f o \mathrm{~F} 2$ variations described above, the Trivandrum $f o \mathrm{~F} 2$ variation shows a totally opposite behaviour, i.e. corresponding decreases in $f o \mathrm{~F} 2 \mathrm{val}-$ ues from its quiet-day values. Regarding the $h^{\prime} \mathrm{F}$ and $h m \mathrm{~F} 2$ variations over Delhi and Trivandrum we may note in Fig. 2 (bottom panels) sharp periodic increases (the positive deviations of $h^{\prime} \mathrm{F}$ and $h m \mathrm{~F} 2$ at both locations reached more than $200 \mathrm{~km})$ and decreases in both $h^{\prime} \mathrm{F}$ and $h m \mathrm{~F} 2$ values from sunset to the morning hours on the night of 20-21 November 2003. For this event the main phase was in progress during the evening hours, where the maximum negative excursion in $D_{s t}$ occurred around midnight, which was promptly followed by a storm recovery phase that lasted until the end of the day (21 November). In the equatorial region only two peaks (enhancements) are observed in $h^{\prime} \mathrm{F}$ and $h m \mathrm{~F} 2$, just before and 
after midnight. One of them occurred during the main phase and the second one just after the start of the recovery phase of the storm. But at the low latitude region, the $h^{\prime} \mathrm{F}$ value shows three major positive deviations, the first one during the main phase, the second one during the $D_{s t}$ maximum negative excursion time and the third one during the recovery phase. It may be noted further that the deviation in $h^{\prime} \mathrm{F}$ and $h m \mathrm{~F} 2$ is less over the low latitude location Delhi as compared to over the equatorial station Trivandrum (see Fig. 2).

\subsection{Magnetic storm of 7 November 2004}

The month of November 2004 witnessed an unusual solar activity with the biggest magnetic storm of 2004 and the fourth biggest of the current solar cycle number 23 (according to the World Data Centre for Geomagnetism at Kyoto University), starting at 05:30 UT (11:00 LT) on 7 November 2004. Figure 3 shows the plots of $D_{s t}$ variations (top panel), and the deviations of $f_{o} \mathrm{~F} 2, h^{\prime} \mathrm{F}$ and $h m \mathrm{~F} 2$ from the quietday values (lower panels) observed over Delhi and Trivandrum during 6-11 November 2004. As seen from Fig. 3, after the initial phase during the local forenoon hours, a sharp decrease in $D_{s t}$ (main phase) sets in with the maximum negative excursion of $D_{s t}$ reaching $-383 \mathrm{nT}$ around local midnight on 7 November 2004, in about ten hours. An equally fast recovery phase followed until the afternoon of 8 November when the recovery slowed down. The slow recovery phases lasted until 9 November morning hours when another storm set in. As seen from Fig. 3, the $D_{s t}$ decrease is rather slow and periodic in this case, reaching a negative maximum excursion of $-300 \mathrm{nT}$ in the post-midnight periods of 9-10 November. The recovery phase of the second storm continued until 14 November or even later. On 7 November, during the period of the main phase of the first storm, though there was not much change in the $f o \mathrm{~F} 2$ values over the equatorial station Trivandrum, a sharp collapse is observed in $f o \mathrm{~F} 2$ (with a maximum decrease up to $10 \mathrm{MHz}$ ) at the low latitude station Delhi from about 12:00 LT, lasting until midnight, before the recovery phase of the storm set in. Subsequently, during the recovery phase of the storm (i.e. on 8 November), the enhancement followed by a depletion in $f o \mathrm{~F} 2$ values is observed over Delhi with opposite behaviour over Trivandrum. Again, throughout the entire day of 9 November 2004, i.e. during the main phase of the second storm, the $f o \mathrm{~F} 2$ values over Delhi and Trivamdrum remain higher than the quiet-day values, with the sharp peak over Delhi in the evening hours when $f o \mathrm{~F} 2$ increases by $10 \mathrm{MHz}$. On the following days, i.e. 10 and 11 November, during the recovery phase of the storm, a good degree of enhancement in foF2 over Delhi and depletion over Trivandrum is also observed for most of the time. For this storm sequence the $h^{\prime} \mathrm{F}$ and $h m \mathrm{~F} 2$ variations can be described as follows: during the main phase of the first storm (see Fig. 3), the fall in $f o \mathrm{~F} 2$ values over Delhi, on 7 November 2004, is almost coincident with the rapid enhancement up to $200 \mathrm{~km}$ in $h^{\prime} \mathrm{F}$ and a small enhancement in the $h m \mathrm{~F} 2$ values, with opposite behaviour at Trivandrum from 14:00 to 00:00 h. Again, during the second
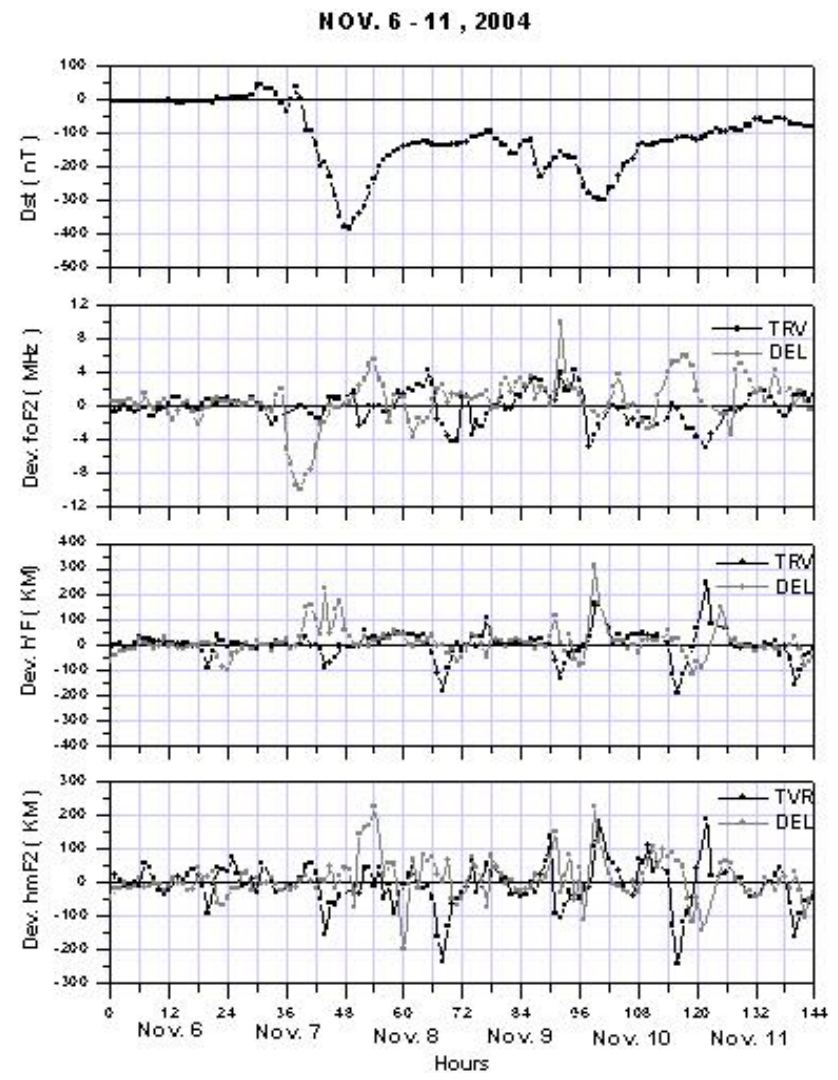

Fig. 3. Shows the deviation in $f o \mathrm{~F} 2, h^{\prime} \mathrm{F}$ and $h m \mathrm{~F} 2$ from the quietday values at the low latitudinal station Delhi in a dark line and the equatorial station Thumba (Trivendrum) in a shaded line, with $D_{s t}$ during the severe magnetic storm of 14 November 2004.

storm on the night of 9-10 November, a sharp rise in $h^{\prime} \mathrm{F}$, and $h m \mathrm{~F} 2$, up to $300 \mathrm{~km}$ and $200 \mathrm{~km}$, respectively, from quiet-day values, is observed over Delhi around the period of the $D_{s t}$ maximum negative excursion. A similar behaviour in $h^{\prime} \mathrm{F}$ and $h m \mathrm{~F} 2$ is also observed over the equatorial station Trivandrum but the magnitude of deviation was comparatively less than that over Delhi. On the 10-11 November night, when the recovery phase of the storm is still continuing, a sharp fall in $h^{\prime} \mathrm{F}$ and $h m \mathrm{~F} 2$ is observed in the pre-midnight hours at both locations, which was followed by sharp increases in the post-midnight hours with a time delay of few hours at Delhi. It may be noted from Fig. 3 that when the value of $h^{\prime} \mathrm{F}$ falls after a rise, an increase in the $f \circ \mathrm{F} 2$ values is observed and this trend of apparently related $f o \mathrm{~F} 2$ and $h^{\prime} \mathrm{F}$ variations over Delhi is similar to those observed during the two other storms discussed above (see Figs. 1 and 2).

3.4 Variations of vertical drift velocity deduced from Delhi Doppler ionograms during the magnetic storms of 29 October 2003 and 20 November 2003

The Delhi IPS-71 Kel-Aerospace modern digital ionosonde has additional facilities, such as the Phase and Doppler Ionogram, HF Spectrum, oblique Sounding, etc., in addition to 

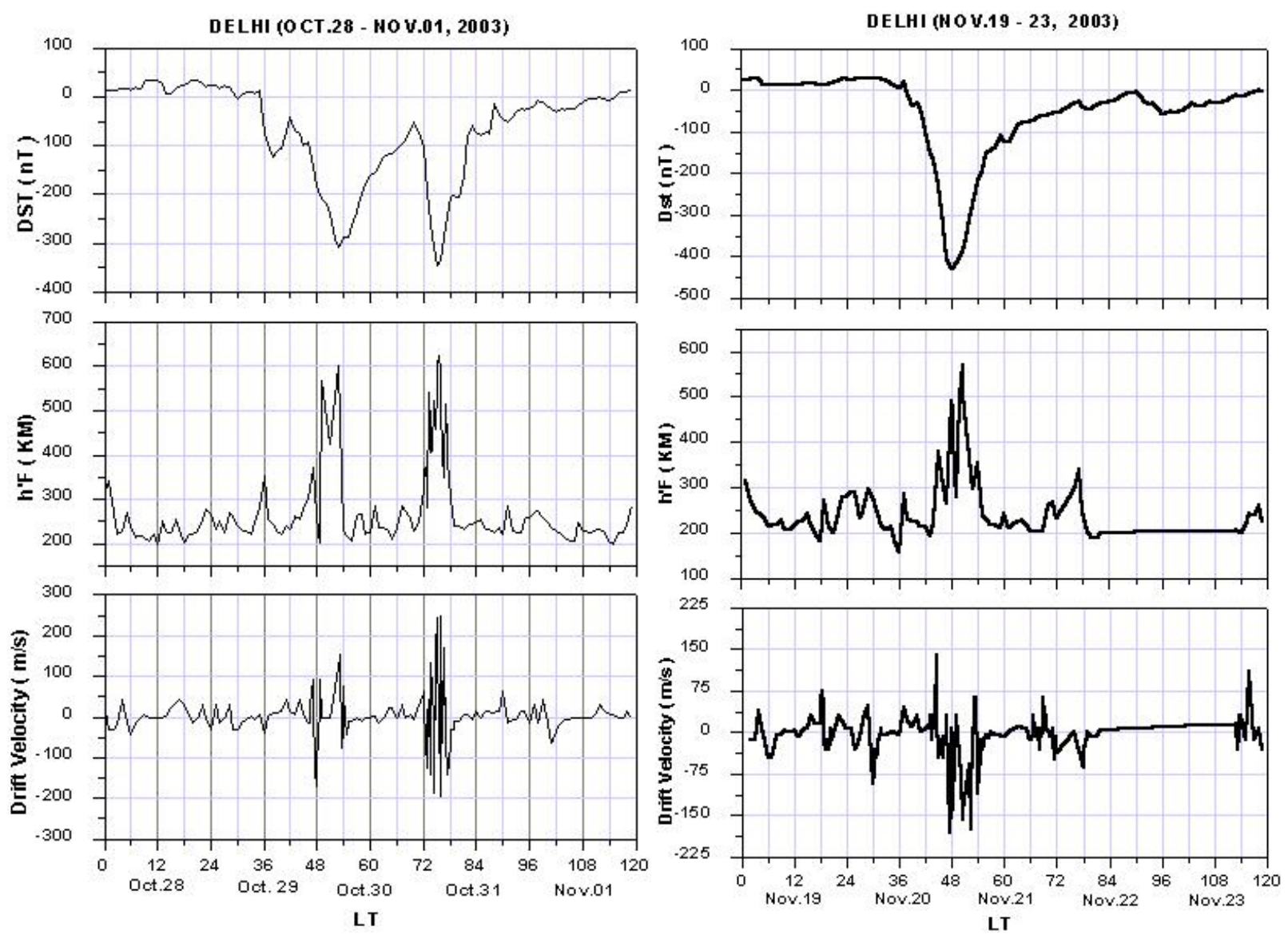

Fig. 4. (a) Shows the variations of $h^{\prime} \mathrm{F}$ and the vertical upward and downward drift velocity deduced by Doppler ionograms (taken every $7.5 \mathrm{~min}$ after the normal amplitude sounding), using a 2 and $4 \mathrm{MHz}$ trace during the nighttime and a 6 and $10 \mathrm{MHz}$ trace during the daytime, with $D_{s t}$ during the severe magnetic storm of 30 October 2003. (b) Shows the variations of $h^{\prime} \mathrm{F}$ and the vertical upward and downward drift velocity deduced by Doppler ionograms (taken every $7.5 \mathrm{~min}$ after the normal amplitude sounding), using a $2 \mathrm{and} 4 \mathrm{MHz}$ trace during the nighttime and a 6 and $10 \mathrm{MHz}$ trace during the daytime with $D_{s t}$ during the severe magnetic storm of 20 November 2003.

the usual Amplitude ionogram. The Ionosonde is being run in three modes, i.e. Amplitude, Doppler and HF Spectrum, every $15 \mathrm{~min}$, around the clock. Doppler sounding is done after every $7.5 \mathrm{~min}$ of amplitude sounding. In the present study, the observed red/blue shifts from Doppler Ionograms are used to calculate roughly the vertical upward/downward F-layer drift velocities. For that purpose, the doppler shift of a 2 or $4 \mathrm{MHz}$ trace during the night and 6 or $10 \mathrm{MHz}$ traces during the daytime are used. Figures $4 \mathrm{a}$ and $4 \mathrm{~b}$, respectively, show the variations of $h^{\prime} \mathrm{F}$ and the vertical upward and downward drift velocity calculated using the Doppler shift with $D_{s t}$ during the magnetic storms of 30 October and 19 November 2003. As noted from these figures, corresponding to the sharp rise (from about $250 \mathrm{~km}$ to $600 \mathrm{~km}$ ) and fall of $h^{\prime} \mathrm{F}$, associated with the maximum negative excursion of $D_{s t}$, vertical upward/downward velocity calculated using Doppler shifts also shows similar fast variations showing values as high as $200 \mathrm{~m} / \mathrm{s}$. Here the upward/downward velocity is not in phase with the $h^{\prime} \mathrm{F}$ variations because of a 7.5-min delay in Doppler sounding with respect to $h^{\prime} \mathrm{F}$ values, but the main point here is to show that there was a sharp upward and downward movement of the F-layer over Delhi due to disturbance electric fields during the severe magnetic disturbances. The above results further confirm the influence of fast changing disturbance electric fields on the F-layer height variations at a station, which is well beyond the daytime EIA crest.

\section{Discussions}

A very wide impact of magnetic storm on F-region ionosphere is observed in the above results. It is also noted that the storm impact on F-region varies with latitude. A rapid and simultaneous increase in the $\mathrm{F}$ layer height $\left(h^{\prime} \mathrm{F}\right.$ and $h m \mathrm{~F} 2$ ), both at equatorial and low latitudes, causes a dramatic ionization collapse/depletion in the equatorial F-region ionosphere, which is followed by an enhancement over the low latitude region during local post-midnight hours of the storm period. An enhancement of F-region ionization at low latitudes is normally observed during the recovery phase of the storm after the sudden rise in $h^{\prime} \mathrm{F}$ and $h m \mathrm{~F} 2$. During the 
growth phase of a storm, an enhancement in both $f o \mathrm{~F} 2$ and height $\left(h^{\prime} \mathrm{F}\right.$ and $\left.h m \mathrm{~F} 2\right)$ over low latitudes and the opposite behaviour over the equatorial region is observed. The above observed enhancement/collapse in F-region ionization and its height can be caused by several factors. During magnetic disturbances, the changes in ionospheric heights with respect to their quiet-time patterns at low latitudes, are produced by vertical plasma drifts driven by a) magnetospheric electric fields penetrating to equatorial latitudes, b) disturbance dynamo electric fields, c) disturbance meridional winds, or d) disturbance zonal winds whose influence is important near sunset. Right over the magnetic equator, only the first two items are responsible for modifications in the vertical plasma drifts while item d) plays a role near sunset (Abdu, 1997). The simultaneous $h^{\prime} \mathrm{F}$ and $h m \mathrm{~F} 2$ rise during the midnight and post-midnight hours at equatorial and low latitudinal regions can be produced mainly by a large disturbance eastward electric field while the effect of disturbance equatorward meridional winds also contribute to changes at low latitude locations. In addition (see Figs. $4 \mathrm{a}$ and $4 \mathrm{~b}$ ), corresponding to the sharp rise and fall of $h^{\prime} \mathrm{F}$ and $h m \mathrm{~F} 2$ over Delhi, associated with the maximum negative excursion of $D_{s t}$, F-layer vertical upward/downward velocity, calculated using Doppler shifts, also shows similar fast variations, with velocity values as high as $200 \mathrm{~m} / \mathrm{s}$. This further confirms the influence of fast changing disturbance electric fields on the F-layer height variations at a station which is well beyond the daytime EIA crest. Also, it is well known that the plasma distribution in equatorial and low latitudes is mainly controlled by $\boldsymbol{E} \times \boldsymbol{B}$ drift through a plasma fountain, which is responsible for the equatorial ionization anomaly. During magnetic disturbances, the disturbance electric fields could enhance the development or inhibition of the equatorial ionization anomaly, whereas the disturbance winds seem to always inhibit EIA (Abdu, 1997). For a better understanding, the effects observed in the present study can be divided into two parts: first, the variation of $f o \mathrm{~F} 2$ and $h^{\prime} \mathrm{F}$ during the pre-midnight storm period and second, the variations in these parameters during the post-midnight period. During the noontime to pre-midnight period, it is found that the value of $f o \mathrm{~F} 2$ increases with increases in $h^{\prime} \mathrm{F}$ and $h m \mathrm{~F} 2$, as compared to the quiet-day value at the low latitude region, while at the equatorial region it is found that the deviation in $f o \mathrm{~F} 2$ is just the opposite to the deviation noted in the $h^{\prime} \mathrm{F}$ and $h m \mathrm{~F} 2$ values. This behaviour of the ionosphere might be due to the wellknown phenomenon of $\boldsymbol{E} \times \boldsymbol{B}$ drift over the equatorial region. The effect of an enhanced fountain seems to be clearly present during the pre-midnight hours of the second storm (Fig. 2), when the $h^{\prime} \mathrm{F}$ and $h m \mathrm{~F} 2$ values at both the equatorial and low latitudinal regions were higher than the quiet-day values. In this case the larger $h^{\prime} \mathrm{F}$ and $h m \mathrm{~F} 2$ enhancement in the equatorial region than at low latitudes would suggest the dominant role of the $\boldsymbol{E} \times \boldsymbol{B}$ effect over the geomagnetic equator. While the $f_{o} \mathrm{~F} 2$ decreases over the equatorial region it increases over the low latitude region, indicating that equatorial plasma transport by the fountain effect did reach up to Delhi latitudes. This result is similar to that observed in the case of a night-time reversal of the electric field to the eastward direction, reported by various researchers (Dabas et al., 1989; Aarons, 1991; Abdu, 2001 and references therein).

The results from the studies of storms 1 and 3 (see Figs. 1 and 3) show that, in the midnight to morning sector, the $h^{\prime} \mathrm{F}$ and $h m \mathrm{~F} 2$ rise over low latitude is slightly higher than that over the equatorial location, whereas in the case of storm 2 (see Fig 2) it was the opposite. This might be due to the fact that storm 2 (see Fig. 2) was a clean one, whereas the other two storms (Figs. 1 and 3) were each followed by another storm during their recovery phases. But still the observed change in heights $\left(h^{\prime} \mathrm{F}\right.$ and $\left.h m \mathrm{~F} 2\right)$ over equatorial and low latitudes is produced mainly by the $\boldsymbol{E} \times \boldsymbol{B}$ drift though the disturbance meridional winds, for a given amplitude of the disturbance electric field, which can further amplify the vertical drift/F-layer height at low latitude if the direction of the winds is equatorward (Abdu, 1997). In the case of the severe storm of 15 July 2000, Sastri et al. (2002) reported a large downward movement of the F-region which occurred simultaneously at locations throughout the equatorial region (dip $0.3-20 \mathrm{~N}$ ) in the Indian midnight sector, with maximum amplitude close to the magnetic equator, which is indicative of a short-lived westward electric field disturbance. Also in the present study, after a initial sudden rise, a similar short-lived, large, downward movement of the F-layer heights (both $h^{\prime} \mathrm{F}$ and $h m$ F2) is observed (see Fig. 2 for the 20 November 2003 storm), with a maximum amplitude over the magnetic equator, which was again followed by a sharp rise in heights.

The simultaneous presence of a strong eastward electric field, as indicated by the increases in $h^{\prime} \mathrm{F}$ and $h m \mathrm{~F} 2$ at the equator, as well as over low latitudes, and the effect of the resulting fountain effects, is responsible for the observed collapse of $f o \mathrm{~F} 2$ at the equatorial location and the enhancement after a time lag over low latitudes, especially in the midnightmorning sector. The present results (see Figs. 1-3), showing simultaneous large enhancements of $h^{\prime} \mathrm{F}$ and $h m \mathrm{~F} 2$, both at equatorial and low latitudes, with a depletion of ionization over the magnetic equator and the enhancement over low latitudes, is due to the upward $\boldsymbol{E} \times \boldsymbol{B}$ drift over the geomagnetic equator, induced by a strong disturbance eastward electric field in the post-midnight period. The above results, about the response of EIA to transient electric fields, shows that the "disturbance fountain" expands EIA to a much wider latitudinal belt than the normal fountain driven by the E/F-layer dynamo electric fields and reconfirms the earlier finding by Abdu et al. (1991) from the Brazilian sector.

\section{Conclusions}

The space weather effect in the equatorial and the low latitudinal F-region ionospheric parameters are studied in some detail during three most severe magnetic storms of recent times, by using digital ionosonde data from two locations, namely Trivandrum, at the magnetic equator, and the Delhi low latitude station, situated north of the daytime equatorial ionization anomaly belt width. During this study several 
striking features are observed. The most important is the simultaneous large enhancement of $h^{\prime} \mathrm{F}$ and $h m \mathrm{~F} 2$, both at equatorial and low latitude locations, associated with the disturbance eastward electric field during the severe magnetic disturbances. At Delhi, fast variations, up to $200 \mathrm{~m} / \mathrm{s}$ in the F-layer vertical upward/downward velocity, calculated using Doppler shifts, associated with the maximum negative excursion of $D_{s t}$, further confirm the influence of rapidly changing disturbance electric fields on the F-layer height variations at a station which is well beyond the daytime EIA crest.

The second most important is the depletion of ionization over the magnetic equator and the enhancement over low latitude, due to the upward $\boldsymbol{E} \times \boldsymbol{B}$ drift at the magnetic equator, induced by strong disturbance eastward electric fields in the post-midnight period. Also, during two storm periods (see Figs. 1 and 3), in the midnight to morning sector, the $h^{\prime} \mathrm{F}$ and $h m \mathrm{~F} 2$ increases over low latitude are slightly higher than those over the equatorial location, whereas in one case (see Fig. 2) it was the opposite. This seems to be caused by the influence of disturbance meridional winds in association with the disturbance eastward electric field, as suggested by Abdu (1991). The presented observation from the Indian zone, about the response of EIA to transient electric fields, shows that the "disturbance fountain" expands EIA to a much wider latitudinal belt than the normal fountain driven by the E/F-layer dynamo electric fields and reconfirms the earlier finding by Abdu et al. (1991) from the Brazilian sector.

Acknowledgements. Topical Editor M. Pinnock thanks M. A. Abdu and another referee for their help in evaluating this paper.

\section{References}

Aarons, J.: The role of the ring current in the generation or inhibition of equatorial F-layer irregularities during magnetic storms, Radio Science, 26, 1131-1149, 1991.

Abdu, M. A., Sobral, J. H. A., de Paula, E. R., and Batista, I. S.: Magnetospheric disturbance effects on the Equatorial Ionization Anomaly (EIA): an overview, J. Atmos. Terr. Phys., 53, 757-771, 1991.

Abdu, M. A.: Major phenomena of the equatorial ionospherethermosphere system under disturbed conditions, J. Atmos. Terr. Phys., 59, 1505-1519, 1997.

Abdu, M. A.: Outstanding problems in the equatorial ionospherethermosphere electrodynamics relevant to spread-F, J. Atmos. Terr. Phys., 63, 869-884, 2001.

Abdu, M. A., Walker, G. O., Reddy, B. M., Sobral, J. H. A., Fejer, B. G., Kikuchi, T., Trevedi, N. B., and Szusxczewicz, E. P.: Electric field versus neutral wind control of the equatorial anomaly under quiet and disturbed conditions; a global perspective from SUNDIAL' 86, Ann. Geophys., 8, 419-430, 1990.

Abdu, M. A., Batista, I. S., Walker, G. O., Sobral, J. H. A., Trivedi, N. B., Paula, E. R. de: Equatorial ionospheric electric Aelds during magnetospheric disturbances: local time=longitude dependences from EITS campaigns. J. Atmos. Terr. Phys., 57, 10651083, 1995.
Burns, A. G., Killeen, T. L., Deng, W. and Carignan, G. R.: Geomagnetic storm effects in the low to middle-latitude upper thermosphere, J. Geophys. Res., 100, 14 673-14691, 1995.

Dabas, R. S. and Jain, A. R.: Geomagnetic storm effects in ionospheric TEC at an equatorial station: contribution of $\mathrm{E} X \mathrm{~B}$ drifts and meridonal neutral winds, Indian J. Radio Space Phys., 14, 100-106, 1985.

Dabas, R. S., Lakshmi, D. R. and Reddy, B. M.: Effect of geomagnetic disturbances on the VHF nighttime scintillation activity at equatorial and low latitudes, Radio Science, 24, 563-573, 1989.

Danilov, A. D.: F2-region response to geomagnetic disturbances, J. Atmos. Terr. Phys., 63, 441-449, 2001.

de Medeiros, R. T. , Abdu, M. A., Batista, I. S.: Thermospheric meridional wind at low latitude from measurements of $\mathrm{F}$ layer peak height, J. Geophys. Res. 102 , 14 531-14 540, 1997.

Dudeney, J. R.: The accuracy of simple methods for determining the height of the maximum electron concentration of the F2-layer from scaled ionospheric characteristics, J. Atmosph. Terr. Phys., 45, 629-640, 1983.

Fesen, C. G., Crowley, G., and Roble R. G.: Ionospheric effects at low latitudes during March 22, 1979, Geomagnetic storm, J. Geophys. Res., 94, 5405-5418, 1989.

Fejer, B. G.: Low latitude electrodynamic plasma drifts, J. Atmos. Terr. Phys., 58, 677-693, 1991.

Kelley, M. C., Fejer, B. G., Gonzales, C. A.: An explanation for anomalous equatorial ionospheric electric fields associated with a northward turning of the interplanetary magnetic field, Geophys. Res. Lett., 6, 301-304, 1979.

Kotadia, K. M. and Ramanathan, K. R.: Effect of geomagnetic disturbances of F2 layer of the ionospheres in low and middle latitudes, Proc. IGY Symp. Held at New Delhi, published by Council of Scientific \& Industrial Research, New Delhi, India, Vol. 1, 176-196, 1962.

Kotadia, K. M.: The great magnetic storm of 11 February 1958 and associated changes in the F2 layer of the ionosphere in low and middle latitudes, J. Atmos. Terr. Phys., 24, 975-988, 1962.

Lakshmi, D. R., Rao, B. C. N., Jain, A. R., Goel, M. K., and Reddy, B. M.: Response of equatorial and low latitude F- region to the great magnetic storm of 13 March 1989, Ann. Geophys., 9, 286290, 1991.

Lakshmi, D. R., Veenadhari, B., Dabas, R. S., and Reddy, B. M.: Sudden post- midnight decrease in equatorial F-region electron densities associated with severe magnetic storms, Ann. Geophys., 15, 306-313, 1997,

SRef-ID: 1432-0576/ag/1997-15-306.

Lima, W. L. C., Becker-Guedes, F., Sahai, Y., Fagundes, P. R., Abalde, J. R., Crowley, G., and Bittencourt, J. A.: Response of the equatorial and low-latitude ionosphere during the space weather event of 2002, Ann. Geophys., 22, 3211-3219, 2004, SRef-ID: 1432-0576/ag/2004-22-3211.

Lobzin, V. V. and Pavlov, A. V.: Solar zenith angle dependencies of F1-layer, NmF2 negative disturbance, and G-condition occurrence probabilities, Ann. Geophys., 20, 1821-1836, 2002a,

\section{SRef-ID: 1432-0576/ag/2002-20-1821.}

Lobzin, V. V. and Pavlov, A. V.: G condition in the F2 region peak electron density: a statistical study, Ann. Geophys., 20, 523 538, 2002b,

SRef-ID: 1432-0576/ag/2002-20-523.

Lynn, K. J. W., Sjarifudin M., Harris T. J., and M. Le Huy: Combined TOPEX/Poseidon TEC and ionosonde observations of negative low-latitude ionospheric storms, Ann. Geophys., 22, 2837-2847, 2004, 
SRef-ID: 1432-0576/ag/2004-22-2837.

Pincheira, X. T., Abdu, M. A., Batista, I. S., and, Richards, P. G.: An investigation of ionospheric responses, and disturbance thermospheric winds, during magnetic storms over South American sector, J. Geophys. Res., 107(A11), 1379, doi:10.1029/2001JA000263, 2002.

Pavlov, A. V., Fukao, S., and Kawamura, S.: F-region ionospheric perturbations in the low-latitude ionosphere during the geomagnetic storm of 25-27 August 1987, Ann. Geophys., 22, 34793501, 2004,

SRef-ID: 1432-0576/ag/2004-22-3479.

Rishbeth, H.: Polarization fields produced by winds in the equatorial F region, Planetary and Space Science, 19, 357-369, 1971.

Sastri, J. H., Jyoti, N., Somayajulu, V. V., Chandra, H., and Devasia, C. V.: Ionospheric storm of early November 1993 in the Indian equatorial region, J. Geophys. Res. 105, 18 443-18 456, 2000.
Sastri, J. H., Niranjan, J., and Subbarao, K. S. V.: Response of the equatorial ionosphere in the Indian (midnight) sector to the severe magnetic storm of July 15, 2000, Geophys. Res. Lett., V. 29, N 13, 1651, doi:10.1029/2002GRL015133, 2002.

Sobral, J. H. A., Abdu, M. A., Gonzlez, W. D., Tsurutani, B. T., Batista, I. S., Clua de Gonzlez, A. L.: Effects of intense storms and substorms on the equatorial ionosphere/thermosphere system in the American sector from ground-based and satellite data, J. Geophys. Res. 102, 14 305-14314, 1997.

Sobral, J. H. A., Abdu, M. A., Yamashita, C. S., Gonzales, A. C. de Batista, I. S., Zamlutti, C. J., and Tsurutani, B. T.: Responses of the low-latitude ionosphere to very intense geomagnetic storms, J. Atmos. S.-P., 63, 965-974, 2001. 